\title{
3D Visual Thinking
}

\author{
Phil Shepherd \\ Researcher \\ $21 \mathrm{~A}$, Rectory Lane \\ Ashtead, Surrey KT21 2BA, UK \\ philshepherdis@gmail.com
}

\section{INTRODUCTION}

The use of visual images to amplify thought processing, has been used by human beings for thousands of years. Probably the most well known form of this is in Egyptian Hieroglyphs.

We have been using graphical images for the past few hundred years by drawing on paper and more recently on a tablet or white-board. Mind mapping is a good example and much work has been done latterly into the psychology of visual thinking.

The investment in $A R$ and VR by large-scale hardware companies such as Microsoft, Google and Facebook is enormous and they will, no doubt, soon be vigorously selling these computer wearables all around the world. Hard as it may be to envisage, new AR hardware could conceivably replace desktops, laptops, tablets and smartphones, but the transition from flat screen to these new 3D environments for mainstream computer users, will be an enormous leap.

In this increasingly complex technical world, it becomes ever more difficult to focus on particular issues and to solve difficult problems with any clarity of thought and purpose. An ideal solution would be a 3D thought processing environment, running on current flat screen technology and using common hardware available to all.

\section{THORTSPACE AS A SOLUTION}

Thortspace uses a compelling immersive 3D environment within which anyone can learn by discovery; It generates an interactive space rich in subject-specific content, where you can not only be inspired to explore your subject at macro and micro levels, but also have the ability to draw on researched information from the internet and add it to your own 3D space. The software platform is also easily searched, accessible via multiple devices, and can be shared and used for collaborative team thinking and research.

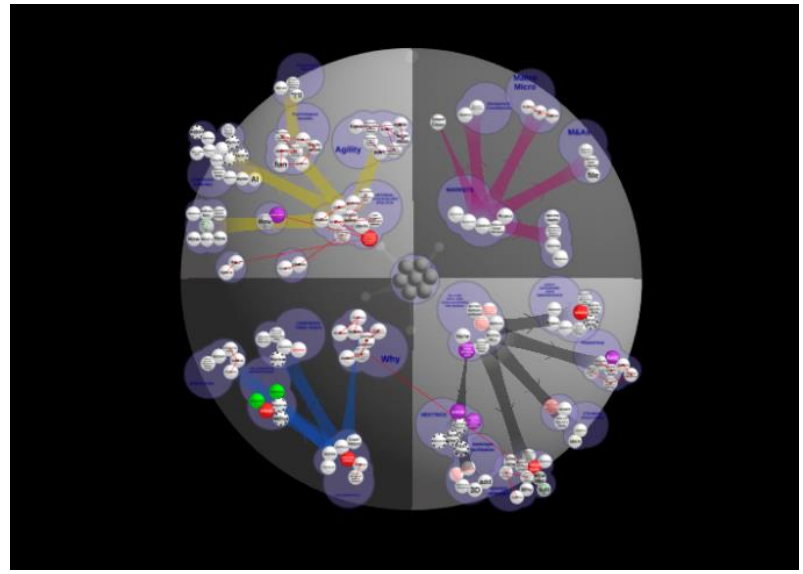

Figure 1: A well-developed Thortspace solution showing how it can deal with a range of complex problems.

Whatever problem or issue there is to be resolved, you begin by rapid brainstorming (free-thinking) in the programme's 'Think Mode', then may examine these thoughts from multiple perspectives. This engenders extra lateral thinking, which is then uploaded to the sphere. It is also easy to add links by dragging and dropping URL's from Websites and cloud-based files and to continue building the process. Each sphere has it's own URL and can be easily published to the web, creating in effect, a 3D spherical website or can be embedded in existing websites. Spheres can also be shared privately with others, so that the programme can be used for collaborative team thinking worldwide, in real or lapsed time and across multiple platforms. These include: Windows, Mac OS, iOS and iPhone, Android for tablets and phones, and Linux.

The programme incorporates a 'Do Mode', which translates the thinking on the sphere into list form for when your thoughts need to be translated into actions. In 'Present Mode' you can create a journey to show milestones in your thinking process. Again Thortspace Journeys can be easily published to the web, from within the programme. Because of its visual nature, this aspect lends itself for presentations to groups at conferences and 
meetings, where delegates are later able to view the animated journey on their own machines.

\section{THORTSPACE IN ACADEMIC RESEARCH, INDUSTRY AND MEDIA}

Professor Dasaratha Rama teaches at Florida International University, where her interests include accounting information systems and data analytics. Her research interests have spanned optimization modelling, internal controls and auditing, corporate governance, and pedagogical innovations. She has published in a wide variety of accounting, information systems, and educational journals. She uses Thortspace to compile stories and discusses its use in her new book Growing Systems of Success. She also uses the software extensively in her teaching and research. She explains:

Every learner plays it forward (compiles, organizes, and shares learning to seek feedback and to help others). Thortspace is an immersive tool for learners to play it forward that is engaging and informative.

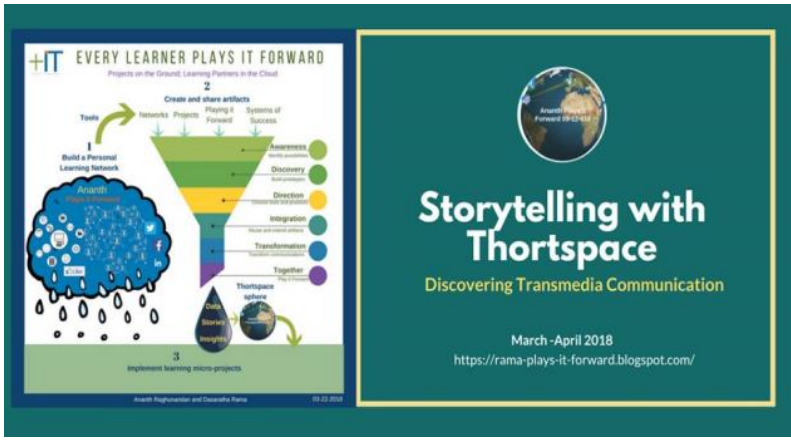

Figure 2: Building a personal learning network with Thortspace and GSS (Growing Systems of Success).

William Morris is Chairman at the International Council for Press and Broadcasting that uses Thortspace to analyse crises in the Middle East and predict trends:

Our methodology is to use the software as framework on which to identify probabilities. Overall we have found Thortspace an invaluable aid to examining situations and brainstorming predictions of possible outcomes.

Kathryn Best is a Research Professor and Author of Design Management: Managing Design Strategy, Process and Implementation. She leads various industry and education initiatives in design, business, creativity, innovation and entrepreneurship:

Thortspace has many different possible applications; however for me the great potential is to help those individuals or organisations in the formative stages of getting their thoughts together. It's sharable, collaborative, intuitive and the best part - it begins to build a roadmap of what you have, to help you realise that a few initial, raw ideas can stimulate more new ideas and shared conversations, and take things much further in a short space of time.

David Keighley, Former BBC producer and controller of public affairs at TV-am. He is also a Judge on the Central Sussex Family Bench and a practising psychotherapist:

\begin{abstract}
I have been lucky enough to have been using Thortspace for almost two years now. From the moment I saw Thortspace on my screen, I sensed excitement, and I was not disappointed. The 3-D linkages generated by the spheres facilitated both new insights and new lines of data management, and - almost magically - I could 'see' the key issues much more clearly. For the future, I know that, in my professional domain, there will be dozens of applications relating to the human mind in all its astonishing complexity. The only problem is knowing where to start!
\end{abstract}

\section{CONCLUSION}

Thortspace is under continual development. $R \& D$ is already under way and a version of the 3D thought processing tool was recently released which could act as a bridge for users from current flat screen to next generation AR/VR technology.

In bringing a demo of Thortspace to EVA London, I hope to generate interesting collaborations with both digital artists and academic institutions, particularly to explore new uses and applications in a creative environment. Generous bursaries on the software can be made available to those who would like to explore all creative possibilities.

\section{REFERENCES}

Acaroglu, L., et al. (2017) 7 Systems Thinking Benefits that Every Organization Needs. https://www.disruptdesign.co/blog/7-systemsthinking-benefits-that-every-organization-needs (retrieved 14 February 2018).

Best, K. (2006) Design Management: Managing Design Strategy, Process and Implementation. AVA Publishing, Lausanne, Switzerland.

Otis, L. (2016) A New Look at Visual Thinking. https://www.psychologytoday.com/us/blog/rethinkin g-thought/201602/new-look-visual-thinking (retrieved 10 March 2018).

Zhu, P. (2018) Future of CIO. http://futureofcio.blogspot.co.uk (retrieved 5 February 2018). 